\title{
Analysis of twelve-month degradation in three polycrystalline photovoltaic modules
}

\author{
T. Lai, B. G. Potter, Jr. and K. Simmons-Potter \\ University of Arizona, Tucson, AZ 85721
}

\begin{abstract}
Polycrystalline silicon photovoltaic (PV) modules have the advantage of lower manufacturing cost as compared to their monocrystalline counterparts, but generally exhibit both lower initial module efficiencies and more significant early-stage efficiency degradation than do similar monocrystalline PV modules. For both technologies, noticeable deterioration in power conversion efficiency typically occurs over the first two years of usage. Estimating PV lifetime by examining the performance degradation behavior under given environmental conditions is, therefore, one of continual goals for experimental research and economic analysis.

In the present work, accelerated lifecycle testing (ALT) on three polycrystalline PV technologies was performed in a full-scale, industrial-standard environmental chamber equipped with single-sun irradiance capability, providing an illumination uniformity of $98 \%$ over a $2 \times 1.6 \mathrm{~m}$ area. In order to investigate environmental aging effects, timedependent PV performance (I-V characteristic) was evaluated over a recurring, compressed day-night cycle, which simulated local daily solar insolation for the southwestern United States, followed by dark (night) periods. During a total test time of just under 4 months that corresponded to a year equivalent exposure on a fielded module, the temperature and humidity varied in ranges from $3{ }^{\circ} \mathrm{C}$ to $40^{\circ} \mathrm{C}$ and $5 \%$ to $85 \%$ based on annual weather profiles for Tucson, $\mathrm{AZ}$. Removing the temperature de-rating effect that was clearly seen in the data enabled the computation of normalized efficiency degradation with time and environmental exposure. Results confirm the impact of environmental conditions on the module long-term performance. Overall, more than $2 \%$ efficiency degradation in the first year of usage was observed for all thee polycrystalline Si solar modules. The average 5-year degradation of each PV technology was estimated based on their determined degradation rates.
\end{abstract}

Keywords: degradation, accelerated lifecycle testing, environmental chamber, polycrystalline, photovoltaic

\section{INTRODUCTION}

Environmentally-caused degradation in power conversion efficiency can significantly undermine the long-term performance and hence the lifetime of photovoltaic (PV) modules ${ }^{[1-2]}$. High relative humidity, extremes in temperature (both high and low), and prolonged exposure to solar radiation are especially responsible for many modes of failure in PV modules including corrosion of devices or contacts, delamination, backsheet cracking, and cell cracking, among others ${ }^{[3-7]}$.

Compared to traditional in-situ test yard studies, in which a centralized, outdoor installation housing a range of module manufacturing technologies is monitored for PV performance over time, a laboratory chamber-based approach produces data by simulating key environmental parameters under accelerated cycle conditions that can significantly reduce the time required to observe degradation trends ${ }^{[8-11]}$. Continuous supervision of the environmental chamber also ensures the availability and quality of test-condition measurements such as module front and back-side temperatures, ambient temperature, humidity, and solar irradiance at the modules, which together enable meaningful interpretation of aging data [11].

Different from stress testing, where modules are subjected to rapid climatic extremes for determining failure modes, accelerated lifecycle testing (ALT) compresses test time while retaining real-time environmental conditions by increasing the average intensity of solar irradiance received by the module to 1 full sun ${ }^{[12-17]}$. Under such realistic

Reliability of Photovoltaic Cells, Modules, Components, and Systems IX, edited by Neelkanth G. Dhere, John H. Wohlgemuth, Keiichiro Sakurai, Proc. of SPIE Vol. 9938, 993800 • (c) 2016 SPIE

CCC code: $0277-786 \mathrm{X} / 16 / \$ 18 \cdot$ doi: $10.1117 / 12.2237527$ 
meteorological conditions, previous work has established a valid connection between the in-situ laboratory experiments and real-time field-based test results among polycrystalline silicon solar modules ${ }^{[11]}$.

In the current study, three polycrystalline PV technologies were selected for the accelerated lifecycle test, whose ambient temperature and humidity conditions were set to parallel, as exactly as possible, climate conditions for a 12 month cycle in Tucson, AZ. Chamber climate data were based on measurements obtained from weather monitoring instrumentation housed at the Tucson Electric Power (TEP)/AzRISE test yard located in Tucson, AZ ${ }^{[10-11]}$. Analyses of the twelvemonth laboratory results obtained from the three selected modules were compared.

\section{EXPERIMENTAL METHODS}

\subsection{Degradation chamber}

The experiments described in this paper utilized a large industrial-standard environmental chamber from Envirotronics (model: WPHL395-1-10-RAC-RMP) which was capable of testing full-size commercial solar panels under continuous, precise control of ambient temperature and relative humidity (Figure 1). Chamber capabilities enabled temperature control from $-30^{\circ} \mathrm{C}$ to $+85^{\circ} \mathrm{C} \pm 1.1^{\circ} \mathrm{C}$. Due to the large internal chamber volume (99" length x 85 " width x 83.75" height), it took approximately 3 minutes for the system to reach a thermal equilibrium across the entire workspace during heating cycles. With the aid of a live load - an external valve allowing additional heat exhaustion - the cooling time was reduced to approximately 1 minute before a reasonably uniform temperature distribution was achieved in the chamber. Humidity control was accomplished through an integrated steamer and atomizer system capable of maintaining a relative humidity of between $20 \%$ and $95 \% \pm 5 \%$.
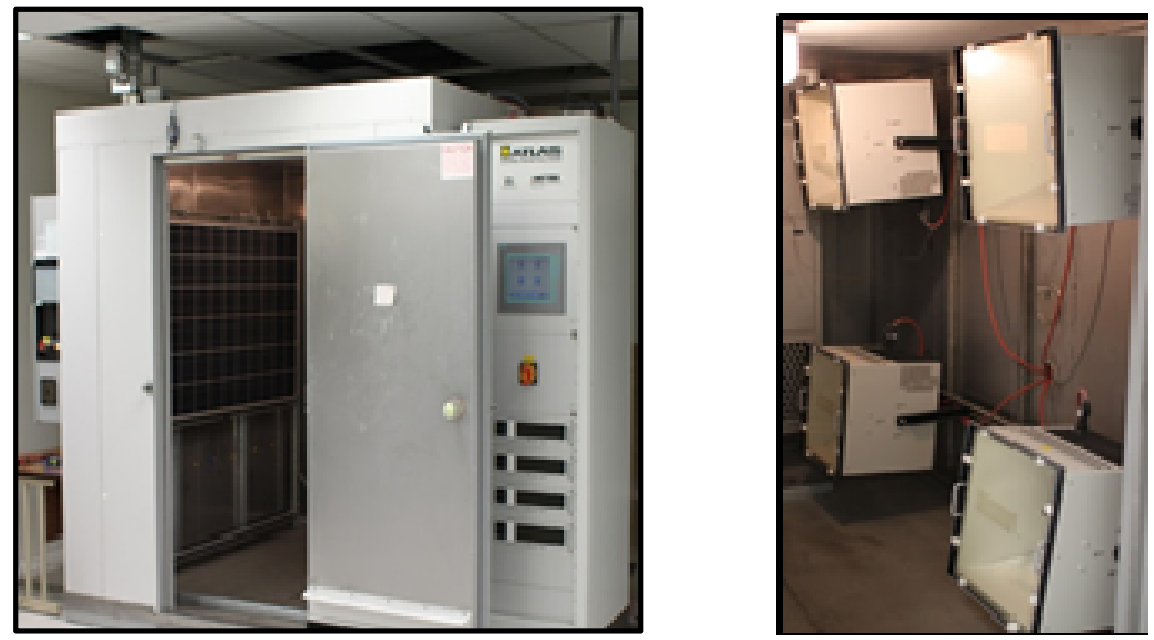

Figure 1. Accelerated lifecycle test chamber: (left) degradation chamber, and (right) metal-halide solar lamps mounted inside the chamber (note: filter glass sheets are not removed from the lamps in this image).

In addition to temperature and humidity control, the environmental chamber was fitted with four filtered UV-visible-IR metal-halide lamps (Atlas SolarConstant 4000) that provided solar spectrum irradiance of up to $1200 \mathrm{~W} / \mathrm{m}^{2}$ with a $95 \%$ uniformity over a $2 \mathrm{~m} \times 1.3 \mathrm{~m}$ area (right image, Figure 1). An Ocean Optics HR2000+ES was utilized to monitor the lamp spectrum at the module surfaces, and the comparison of this data to the AM1.5 standard is shown in Figure 2 below. As can be seen in the figure, the spectral composition of the lamp emission closely matched the AM1.5 spectrum across the UV and short-wavelength visible portion of the spectrum but somewhat underestimated the red-NIR portion of the spectrum. Additional details of the environmental test chamber are given in [11]. 
Temperature, humidity and solar irradiance set points were programmed into time-based monthly cycles to provide external control of exposure conditions throughout testing. To probe system function under environmental exposure, the chamber was also designed with real-time feedback of environmental conditions (temperature, humidity, PV module backside temperature, solar irradiance) for process control.

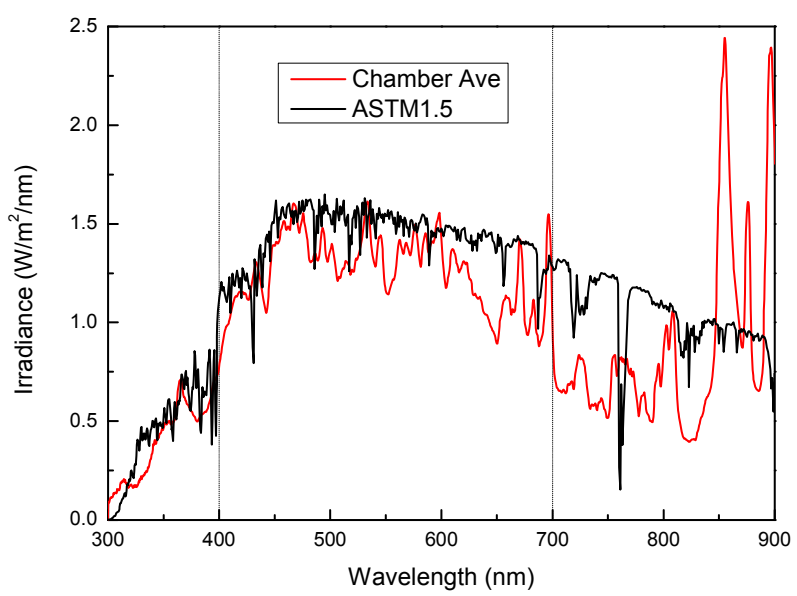

Figure 2: Lamp emission spectrum compared to the AM 1.5 data in ASTM G173-03.

Electrical data were gathered using a Daystar DS-100C I-V curve tracer connected to the module accompanied by IVPC software. Open circuit voltage $\left(\mathrm{V}_{\mathrm{OC}}\right)$, short circuit current $\left(\mathrm{I}_{\mathrm{SC}}\right)$, maximum power, maximum power voltage $\left(\mathrm{V}_{\mathrm{MP}}\right)$, maximum power current $\left(\mathrm{I}_{\mathrm{MP}}\right)$, and fill factor $(\mathrm{FF})$ were obtained during each sweep performed by the tracer. In all cases, fill factor (FF) was defined as the maximum power divided by the product of the open circuit voltage and the short circuit current (i.e.: $\left.\mathrm{FF}=\operatorname{Pmax} /\left(\mathrm{V}_{\mathrm{OC}} \mathrm{I}_{\mathrm{SC}}\right)=\left(\mathrm{V}_{\mathrm{MP}} \mathrm{I}_{\mathrm{MP}}\right) /\left(\mathrm{V}_{\mathrm{OC}} \mathrm{I}_{\mathrm{SC}}\right)\right)$. The module efficiency was calculated using the standard definition of Pmax/(EA), where $\mathrm{E}$ was the total irradiance incident on the module in $\mathrm{W} / \mathrm{m}^{2}$, and A was the module active surface area $\left(\mathrm{m}^{2}\right)$.

\subsection{Accelerated Lifecycle Test (ALT)}

In order to closely match in-situ exposure conditions for fielded PV modules, the environmental set points for the degradation chamber were programmed to mimic the temperature/humidity weather profile for Tucson, AZ. For the modules reported in this paper, two similar profiles were utilized. In the first case, typical monthly temperature, humidity and solar insolation day/night averages were used as chamber set points for an equivalent one-year exposure (January to December), while in the second case weekly averaged environmental data collected over a 12 month period at the test yard in Tucson, AZ from October 2013 to October 2014 were utilized. Details of the test parameters and set points are given in $[11,13]$ for the two test conditions, respectively. The test method employed for determining the duration of solar irradiance during each of the experiments utilized the total energy incident on a module under typical field conditions in order to accelerate the rate of data acquisition beyond real-time without artificially increasing the maximum solar flux received at the module (i.e.: no solar concentration was performed). Specifically, in the testing performed here, modules in the chamber were exposed to a constant irradiance of $1000 \mathrm{~W} / \mathrm{m}^{2}$ during each daytime cycle of the test. Since solar irradiance on a module in the field will vary with the time of day, the time period for each daytime test cycle was determined based upon the average total insolation received each day of the year ${ }^{[18]}$. Using the $1000 \mathrm{~W} / \mathrm{m}^{2}$ supplied by the chamber sources, the "daily" exposure was adjusted to provide solar insolation levels consistent with these averages. Each daytime exposure was followed by a one-hour nighttime dark soak period enabling the cyclic variation in temperature and humidity conditions from day to night to be simulated. Under these conditions, the overall acceleration factor for the test cycle was $\sim 3.6 \mathrm{X}$ (i.e. ALC test time $=$ Field time/3.60). 
The chosen solar module types being tested in the degradation chamber were all commercial polycrystalline PV modules. Their electrical and performance characteristics at STC for each module provided by their respective manufacturers are tabulated in Table 1. Variation in rated power between the three modules tested does not always scale with cell area (see Modules B and C).

Table 1. Nameplate power, cell area, and temperature coefficient data for all three polycrystalline PV modules.

\begin{tabular}{|c|c|c|c|c|c|}
\hline \multirow{2}{*}{ Module } & \multirow{2}{*}{ Rated Power (W) } & \multirow{2}{*}{ Cell Area $\left(\mathbf{m}^{\mathbf{2}} \mathbf{)}\right.$} & \multicolumn{3}{|c|}{ Temperature Coefficient $\left.\mathbf{( \% /} / \mathbf{C}^{\mathbf{C}}\right)$} \\
\cline { 4 - 6 } & & $\mathbf{P}_{\mathbf{M P}}$ & $\mathbf{V}_{\mathbf{O C}}$ & $\mathbf{\mathbf { I } _ { \text { SC } }}$ \\
\hline $\mathbf{A}$ & 295 & 1.752 & -0.43 & -0.31 & +0.056 \\
\hline $\mathbf{B}$ & 250 & 1.46 & -0.43 & -0.32 & +0.047 \\
\hline $\mathbf{C}$ & 270 & 1.46 & -0.39 & -0.31 & +0.045 \\
\hline
\end{tabular}

\section{RESULTS AND DISCUSSION}

The weekly weather set points were programmed on the chamber control tower to precisely re-create the environmental conditions as described above, so that the tested modules in the degradation chamber experienced a realistic sequential climate changes analogous to the local weather. Chamber data were taken with the curve tracer every fifteen minutes to obtain the power output as well as other important parameters (e.g. lamp irradiance, module temperature etc.). Figures 3 through 5 show the raw output power as a function of equivalent solar exposure time for modules $\mathrm{A}$, B, and $\mathrm{C}$, respectively along with module backside temperatures. Notice that the Module A exposure cycle started in January, while Module B and Module $\mathrm{C}$ began their cycles in an equivalent October month. Although different initial months depict different temperature profile shapes, they all exhibit a higher power output under the colder, winter-time conditions (two end points for Module A, Fig. 3, and around 500 exposure hours for Module B, C, Fig. 4 and Fig. 5 , respectively) and a lower efficiency during the simulated summer months (around 1000 hours for Module A, and 1500 hours for Module B, C). Hence, the clear effects of temperature de-rating can be seen in each of the figures.

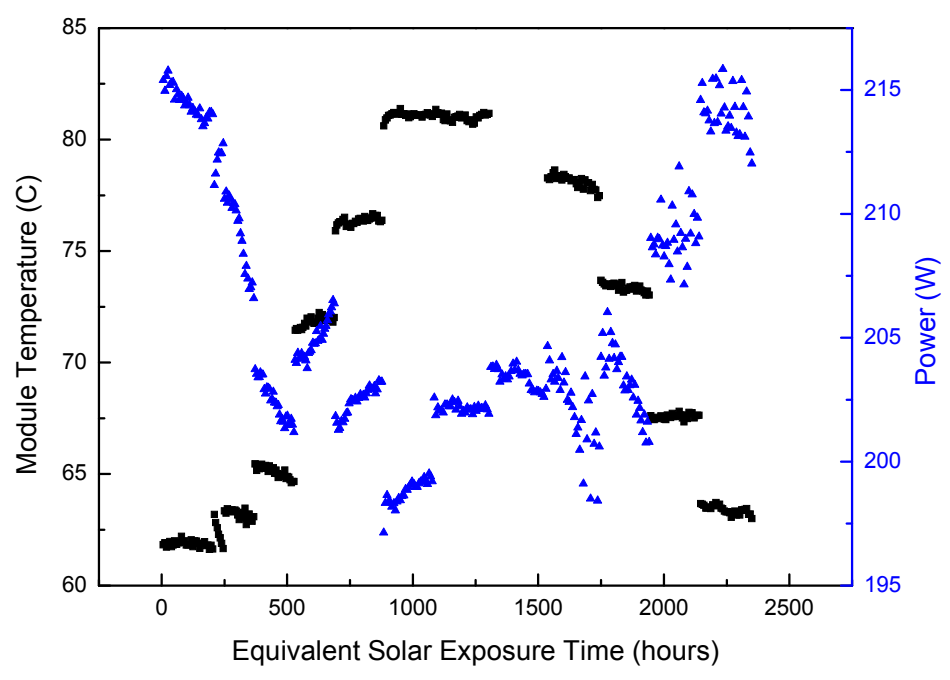

Figure 3: Module temperature profile (left axis, black data points) and raw power output data (right axis, blue data points) for polycrystalline Si PV Module A. 


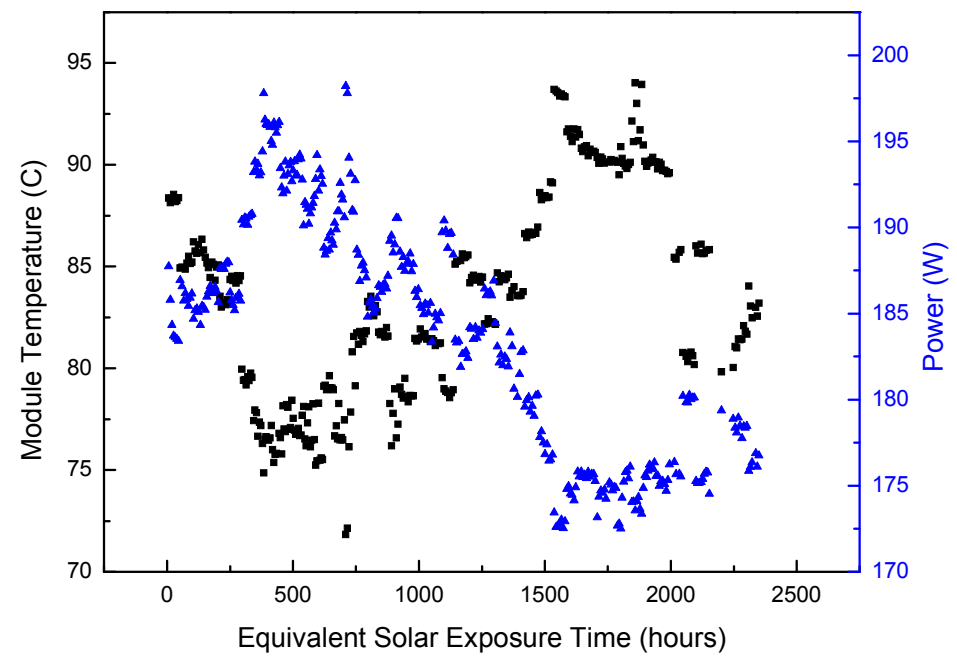

Figure 4: Module temperature profile (left axis, black data points) and raw power output data (right axis, blue data points) for polycrystalline Si PV Module B.

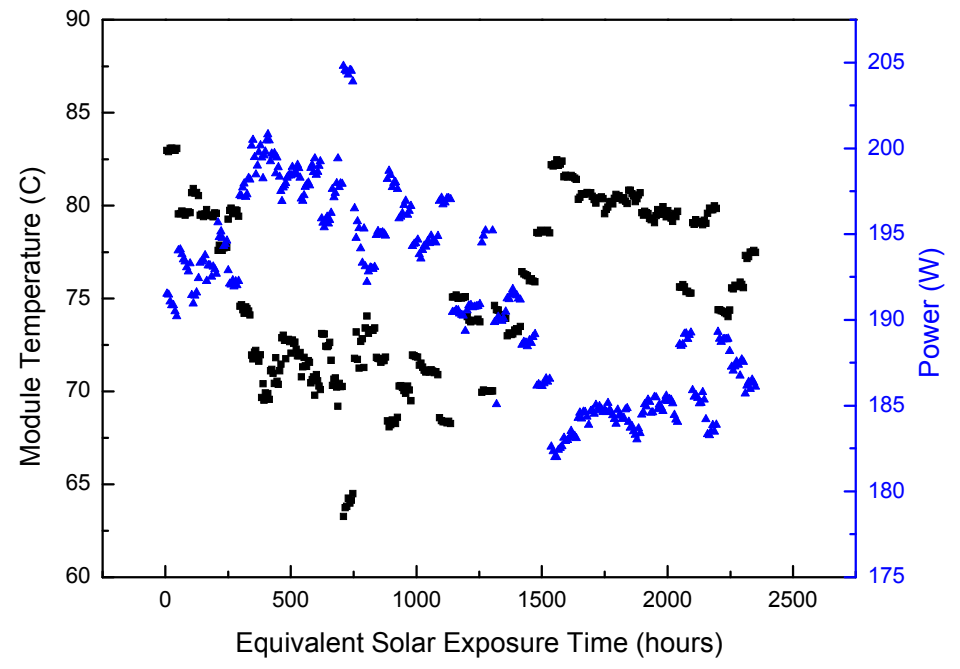

Figure 5: Module temperature profile (left axis, black data points) and raw power output data (right axis, blue data points) for polycrystalline Si PV Module C.

As monthly average temperatures varied during the test period, the expected changes in energy conversion efficiency, and hence power produced, were observed. Since it is well understood that photovoltaic module output is influenced by module temperature (with lower efficiencies corresponding to higher temperatures ${ }^{[19-21]}$ ), as seen in the figures, the development of a true interpretation of module performance degradation must extract aging effects from simple variations in module output resulting from such ambient temperature variations. The raw efficiency was computed using 
the standard definition of efficiency, $\eta=\mathrm{P} /(\mathrm{EA})$, where A represented a constant of cell area in $\mathrm{m}^{2}$ (see Table 1). The temperature control inside the chamber enabled the measurement of both the ambient and the backside temperatures measured in the chamber which were found to form a linear relationship. Based on the backside temperature, the calculated temperature de-rating efficiency coefficients for all three polycrystalline $\mathrm{Si}$ modules $\left(\mathrm{A}:-0.40 \% /{ }^{\circ} \mathrm{C}, \mathrm{B}\right.$ : $0.46 \% /{ }^{\circ} \mathrm{C}$ and $\mathrm{C}:-0.39 \% /{ }^{\circ} \mathrm{C}$ ) were determined to be comparatively close to the manufactures' specified values (A: $0.43 \% /{ }^{\circ} \mathrm{C}$, B: $-0.43 \% /{ }^{\circ} \mathrm{C}$, and $\mathrm{C}:-0.39 \% /{ }^{\circ} \mathrm{C}$ in Table 1$)$. These data were then applied to the raw efficiency data in order to interpret the temperature-derating-corrected time-dependent module degradation. Figure 6, below, shows the temperature-corrected module efficiency degradation for the three polycrystalline Si PV modules.

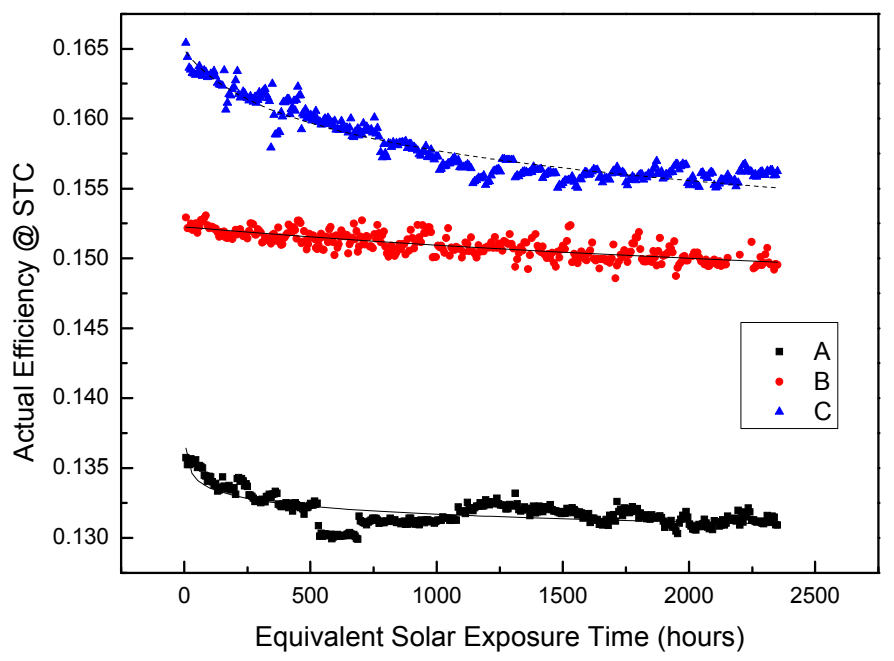

Figure 6. Performance efficiency of the three polycrystalline Si modules after being corrected with the experimentally determined temperature coefficients.

Examination of the figure shows that Module A exhibited an efficiency reduction of 0.0028 in absolute efficiency (from 0.1349 to 0.1321 ), or equivalently a $2.08 \%$ degradation in terms of the normalized efficiency; Module B exhibited 0.0037 in absolute efficiency (from 0.1525 to 0.1488 ), or a $2.4 \%$ degradation in normalized efficiency; and Module C exhibited an efficiency reduction of 0.0092 (from 0.1654 to 0.1562 ), or $5.6 \%$ normalized degradation. Overall, more than $2 \%$ normalized degradation in the first year of usage was observed for all three tested polycrystalline Si modules after the temperature de-rating effect was compensated.

Based on the extracted normalized degradation rates, Module $\mathrm{C}$ had the highest degradation rate $(5.6 \%)$, followed by Module B (2.4\%) and Module A (2.08\%) after a one-year equivalent aging cycle. It is significant, however, that despite the larger overall degradation exhibited by Module $\mathrm{C}$, that particular polycrystalline module type had the highest initial actual efficiency and remained the most efficient even after one equivalent year of environmental aging. Clearly, then, the absolute one-year efficiency degradation may not be the only relevant evaluation metric for assessing relative advantages/disadvantages among PV module types.

Degradation rate (Figure 6) data can be more fully understood by applying fitting functions to the data. In all cases, the data could be accurately fit with double exponential curves in which one time constant represented the rapid, initial decrease in PV module efficiency that is associated with the first 500-1000 hours (often referred to as the "burn-in" period) of one-sun equivalent solar exposure time, and the other represented the sustained, long-term, environmentallyinduced, long time constant, efficiency degradation: $\eta=\eta_{0}+A_{1} e^{-t / \tau_{1}}+A_{2} e^{-t / \tau_{2}}$, where $\eta_{0}$ is the offset, $A_{1}$ and $A_{2}$ are the amplitudes, and $\tau_{1}$ and $\tau_{2}$ represent the decay constants (see Table 2 for derived values). With one full year of experimental data, although not enough for an accurate lifetime prediction, an estimation of 5 -year degradation could be 
assessed. The extrapolation simply extended the time variable five times longer and fed it to a generated tail function that best described the experimentally-determined efficiency trend close to the end of year 1.

Table 2. Time constants determined based on the best-fit function for all three polycrystalline Si modules.

\begin{tabular}{|c|c|c|c|c|c|}
\hline Module & Offset & $\mathbf{A}_{\mathbf{1}}$ & $\boldsymbol{\tau}_{\mathbf{1}}$ & $\mathbf{A}_{\mathbf{2}}$ & $\boldsymbol{\tau}_{\mathbf{2}}$ \\
\hline $\mathbf{A}$ & 0.12966 & 0.00179 & 270.4171 & 0.00272 & 3254.305 \\
\hline $\mathbf{B}$ & 0.14912 & 0.00148 & 254.5753 & 0.00224 & 3154.873 \\
\hline $\mathbf{C}$ & 0.1542 & 0.00337 & 117.9207 & 0.00385 & 2348.853 \\
\hline
\end{tabular}

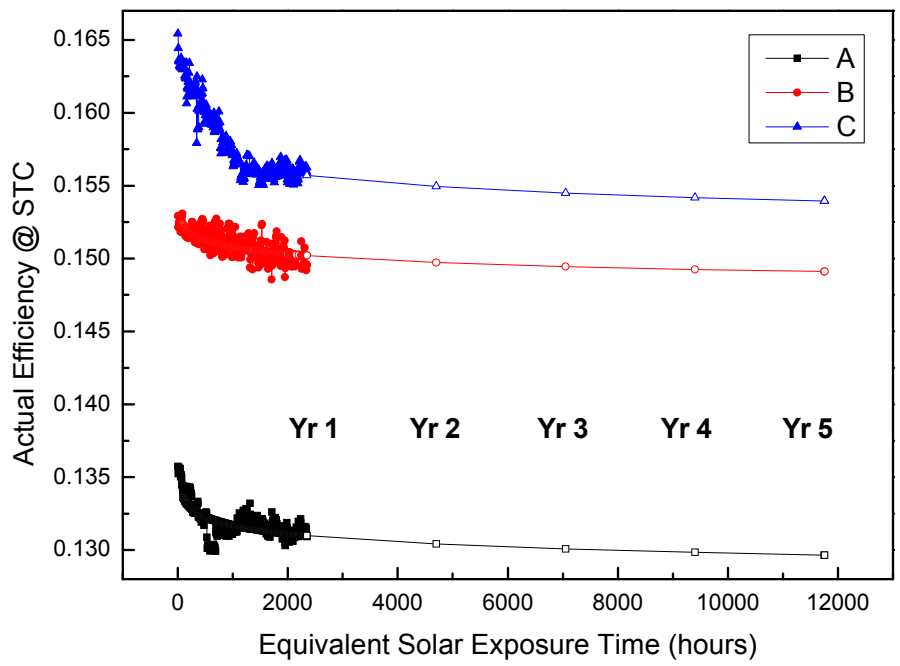

Figure 7. The estimated efficiency by the end of year 5 using a best-fit model for the tail of the degradation trend.

Figure 7 shows extrapolated best-fit data for 5 -year efficiency performance on all three modules. At the end of year 5 , Module A was estimated to have an efficiency of 0.12990 (equivalent to a $0.12990 / 0.1349 \approx 96.2936 \%$ normalized efficiency), which gave an average degradation of $0.74 \% /$ year. The year 5 efficiency of Module B was estimated at 0.14914 (a normalized efficiency of $0.14914 / 0.1525 \approx 97.7967$ ), which corresponded to an average degradation of $0.44 \%$ year. The efficiency prediction for Module $\mathrm{C}$ was 0.15394 (a normalized efficiency of $0.15394 / 0.1654 \approx$ $93.0713 \%$ ), resulting in an average degradation of 1.39\%/year. It is notable that the long-tail slopes of the fits for all of the modules are similar in the figure. Thus, it may be concluded that the significant variations in the computed five-year average annual degradation rates among manufacturer types resulted, primarily, from the magnitude of the initial "burnin" degradation of the modules.

\section{CONCLUSIONS}

With the aid of a full-scale, controlled, environmental chamber, three different commercially-available, polycrystalline Si modules were subjected to accelerated lifecycle testing of photovoltaic degradation under analogous environmental conditions of Tucson, AZ. In all cases, the PV modules exhibited significant initial "burn-in" degradation during the first 500-1000 hours of testing due to exposure to the temperature, humidity and solar insolation conditions provided. Normalized efficiency degradation ranging from $2 \%$ to $5.6 \%$ were observed after the one-year equivalent test. In addition, slower, long-term environmental degradation rates were evaluated from the data taken for $>1000$ equivalent hours of environmental exposure and fits to these data were used to estimate five-year efficiency losses for the modules. 
For all modules, the five-year efficiency loss was determined to average to lower than $1.4 \%$ (A: $0.74 \% / y e a r, B$ : $0.44 \% /$ year, and C: $1.39 \% /$ year).

\section{ACKNOWLEDGEMENTS}

This work was supported by the Arizona Research Institute for Solar Energy (AzRISE), the University of Arizona Renewable Energy Network (UA REN), and by Tucson Electric Power Corporation (TEP).

\section{REFERENCES}

[1] Aste, N., Del Pero, C., and Leonforte, F., "The first Italian BIPV project: Case study and long-term performance," Solar Energy 134, 340-352 (2016).

[2] Ndiaye, A., Charki, A., Kobi, A., Ke'be, C.M., Ndiaye, P. A., and Sambou, V., "Degradations of silicon photovoltaic modules: A literature review," Solar Energy 96, 140-151 (2013).

[3] Laronde, R., Charki, A., and Bigaud, D., "Lifetime estimation of a photovoltaic module subjected to corrosion due to damp heat testing," Journal of Solar Energy Engineering 135(2), 8 pages (2013).

[4] Cuddihy, E. F., "The aging correlation $(\mathrm{RH}+\mathrm{t})$ : relative humidity $(\%)+$ temperature $(\mathrm{C}), "$ Corrosion Science. 1(5), 463-474 (1987).

[5] Sugimura, R. S., Wen, L. C., Mon, G. R., and Ross, R. G. J., "Test techniques for voltage/humidity-induced degradation of thin-film photovoltaic modules," Solar Cells 28, 103-114 (1990).

[6] Jeong, J.-S., Park, N., and Han, C., "Field failure mechanism study of solder interconnection for crystalline silicon photovoltaic module," Microelectronics Reliability 52, 2326-2330 (2012).

[7] Bhandari, K. P., Collier, J. M., Ellingson, R. J., and Apul, D. S., "Energy payback time (EPBT) and energy return on energy invested (EROI) of solar photovoltaic systems: A systematic review and meta-analysis," Renewable and Sustainable Energy Reviews. 47, 133-141 (2015).

[8] Green, M. A., "Silicon photovoltaic modules: a brief history of the first 50 years," Progress in Photovoltaics 13, 447-455 (2005).

[9] Coello, J., "Degradation of crystalline silicon modules: a case study pm 785 samples after two years under operation," Proc. $26^{\text {th }}$ EU PVSEC, 3500-3503 (2011).

[10] Cronin, A. D., Brooks, A., Cormode, D., Hardesty, G., and Lonij, V. P. A., "Performance reviews from the Tucson Electric Power solar test yard," Proc. 37 $7^{\text {th }}$ IEEE PVSC, 2351-2356 (2011).

[11] Lai, T., Biggie, R., Brooks, A., Potter, Jr., B. G., and Simmons-Potter, K., "Environmental aging in polycrystallineSi photovoltaic modules: Comparison of chamber-based accelerated degradation studies with field-test data," Proc. SPIE 9563, 956309-1 - 956309-8 (2015).

[12] Fedor, G. R., and Brennan, P. J., [Durability Testing of Nonmetallic Materials], ASTM, West Conshohocken, 91-97 (1996).

[13] Biggie, R., Lai, T., Huang, W.-J., Potter, Jr., B. G., and Simmons-Potter, K., "Comparison of environmental degradation in Hanwha $295 \mathrm{~W}$ and SunPower $320 \mathrm{~W}$ photovoltaic modules via accelerated lifecycle testing," Proc. SPIE 9179, 917906-1 - 917906-9 (2014).

[14] Osterwald, C. R., and McMahon, T. J., "History of accelerated and qualification testing of terrestrial photovoltaic modules: A literature review," Prog. Photovolt: Res. Appl. 17(1), 11-13 (2009).

[15] Zielnik, A. F., and Dumbleton, D. P., [Photovoltaic Module Weather Durability \& Reliability Testing], Atlas Material Testing Technology LLC, Chicago, 8-22 (2012).

[16] Ott, T., Walter, T., Hariskos, D., Kiowski, O., and Schaffler, R., "Accelerated aging and contact degradation of CIGS solar cells," IEEE Journal of Photovoltaics 3(1), 514-519 (2013).

[17] Haillant, O., "Accelerated weathering testing principles to estimate the service life of organic PV modules," Solar Energy Materials and Solar Cells 95(5), 1284-1292 (2011).

[18] NREL, "30-Year Average of Monthly Solar Radiation, 1961-1990," 1990, http://rredc.nrel.gov/solar/old_data/nsrdb/1961-1990/redbook/sum2/23160.txt (Aug 2016).

[19] Jordan, D. C., Wohlgemuth, J. H., and Kurtz, S. R., "Technology and climate trends in PV module degradation," Proc. $27^{\text {th }}$ EU-PVSEC, 3118-3124 (2012). 
[20] Loper, P., Pysch, D., Richter, A., Hermile, M., Janz, S., Zacharias, M., and Glunz, S. W., "Analysis of the temperature dependence of the open-circuit voltage," Energy Procedia 27, 135-142 (2012).

[21] Skoplaki, E., and Palyvos, J. A., "On the temperature dependence of photovoltaic module electrical performance: A review of efficiency/power correlations," Solar Energy 83(5), 614-624 (2009).

[22] Jordan, D. C., and Kurtz, S. R., "The dark horse of evaluating long-term field performance," IEEE Journal of Photovoltaics 4(1), 317-323 (2014).

[23] Kuo, C. F., "Long-term outdoor measurement of photovoltaic system and performance analysis by PVUSA model," M.S. thesis, Dept. Energy Engineering, National Central University, TaoYuan, 96 pages (2015).

[24] Kamei, A., Yoshida, S., Takakura, H., and Minemoto, T., "Ten years outdoor operation of silicon based photovoltaic modules," Renewable Energy (65), 78-82 (2014).

[25] Ndiaye, A., Charki, A., Kobi, A., M., Ke'be, Ndiaye, P.A., and Sambou, V., "Degradations of silicon photovoltaic modules: A literature review," Solar Energy 96, 140-151 (2013).

[26] Phinikarides, A., Kindyni, N., Makrides, G., and Georghiou, G. E., "Review of photovoltaic degradation rate methodologies," Renewable and Sustainable Energy Reviews 40, 143-152 (2014).

[27] Phinikarides, A., Makrides, G., and Georghiou, G.E., "Comparison of analysis methods for the calculation of degradation rates of different photovoltaic technologies," Proc. $28^{\text {th }}$ EU-PVSEC, 3973-3976 (2013).

[28] Sharma, V., and Chandel, S., "Performance and degradation analysis for long term reliability of solar photovoltaic systems: A review," Renewable and Sustainable Energy Reviews 27, 753-767 (2013).

[29] Sorloaica-Hickman, N. Davis, K., Leyte-Vidal, A., Kurtz, S. R., and Jordan, D. C., "Comparative study of the performance of the field-aged photovoltaic modules located in a hot and humid environment," Proc. $38^{\text {th }}$ IEEE PVSC, 2376-2381 (2012). 